\section{ORAL CANCER LEARNING RESOURCE LAUNCHED}

Smile-on have produced a new programme for dental professionals called 'Oral Cancer: Prevention, Examination and Referral'.

After completion of the course, healthcare professionals will be: up to date on current oral cancer epidemiology; aware of the importance of routine opportunistic screening for oral cancer and the unique role they play in early detection; able to identify patients at particular risk and provide appropriate advice; able to identify suspicious lesions; aware of the appropriate referral procedure; confident in communicating concerns to patients; better able to understand the disease from a patient's perspective; and able to comprehend the outcome following referral to a specialist.

Smile-on have produced the 90-minute essential learning resource in collaboration with the Postgraduate Deanery for Kent, Surrey and Sussex and The British Dental Health Foundation.

Reader response number 55

\section{TOP TRADE FAIR RETURNS TO COLOGNE}

The 2011 International Dental Show (IDS) will open its doors on 22 March 2011 for five days of dental innovation in Cologne, Germany. This leading world dental fair is once again expected to set new benchmarks and offer over 100,000 trade visitors from around 140 countries an unrivalled forum for networking within the international dental market.

Visitors to IDS 2011 will benefit from the event's tremendous range, with around 1,900 exhibitors from about 60

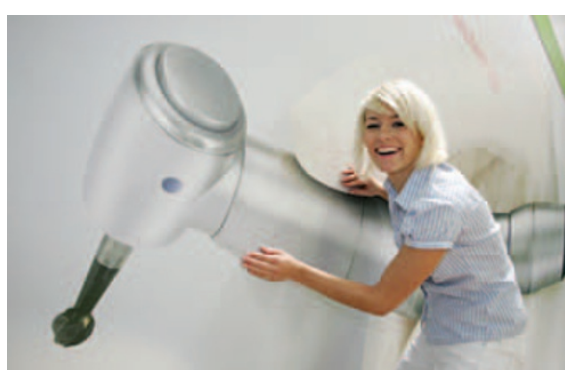

\section{AVOID MISSING VALUABLE CALLS}

Denticom is a unique managed service specifically designed for dental practices, offering the practitioner a chance to have a $24 / 7$ receptionist and ensure excellent client communication.

The Perfect Partner facility allows patients to book, amend or cancel their nations due to attend. Information on the latest developments and products will be available first hand for all disciplines in the areas of dental medicine, diagnostics, digital workflow, CAD/ CAM systems, external services and much more, including specialists from laboratories, industry, trade and media. Live demonstrations of the latest technology will also be taking place.

This year, for the first time, the IDS is offering its own mobile app for iPhone, Blackberry and other operating systems. The app contains a catalogue and navigation system that guides the visitor through the halls and to the corresponding exhibition stands. In addition, the app provides information on the catering services and support programme at the event. The app is available to users free of charge from the IDS website at http://english.ids-cologne.de.

Reader response number 56

appointments over the telephone at any time of day or night. The system integrates seamlessly with your practice's electronic appointment book, and at times of high call volume, messages are played promoting your services and informing the patient of their place in the queue.

Denticom's Patient Point allows patients to check themselves in for

\section{ANTIBACTERIAL UPHOLSTERY}

All Plinth 2000 couch coverings are vinyl, washable, stain resistant and capable of withstanding disinfection with a chlorine-based product.

Most of its standard upholstery grades incorporate a patented antibacterial additive, which provides longlasting effectiveness against MRSA, Clostridium difficile, Escherichia coli and other harmful bacteria and is also resistant to mould and odours.

One area of particular risk is upholstery damage, through cuts, tears or poor cleaning technique. Plinth recommends regular inspection and servicing, with the option of replacing damaged vinyl as soon as any problem occurs. Plinth 2000 has designed its couch upholstery for ease and speed of replacement. It also offers the option of upgrading older models to antibacterial upholstery.

Plinth 2000 accessories include paper roll holders, tailor-made plinth covers and foot controls for electric height adjustment.

Reader response number 57

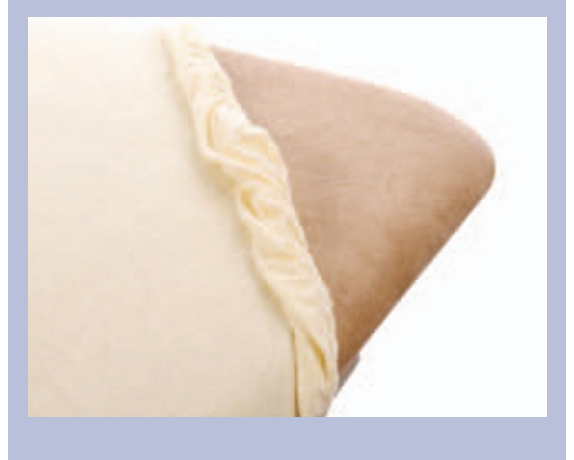

appointments, reducing congestion at reception and giving your staff the time to answer the telephone. The Patient Point is easy to programme with information specific to your practice such as opening hours, photographs and prices and can be loaded with questionnaires to facilitate good practice management. Reader response number 58 